\title{
Hyperpolarization-Activated Cation Current Contributes to Spontaneous Network Activity in Developing Neocortical Cultures
}

\author{
Julia Klueva Ana D. de Lima Susanne Meis Thomas Voigt Thomas Munsch \\ Institut für Physiologie, Medizinische Fakultät, Otto-von-Guericke-Universität, Magdeburg, Germany
}

\section{Key Words}

Cortex · Interneuron - Cell culture - Pacemaker current •

Network activity

\begin{abstract}
The mechanisms underlying spontaneous burst activity (SBA), appearing in networks of embryonic cortical neurons at the end of the first week in vitro, remain elusive. Here we investigated the contribution of the hyperpolarization-activated cation current $\left(I_{h}\right)$ to SBA in cortical cultures of GAD67GFP mice. $I_{h}$ current could be detected in GFP-positive large GABAergic interneurons (L-INs) and glutamatergic principal neurons (PNs) as early as DIV 5. Under current-clamp conditions, blockers of $\mathrm{I}_{\mathrm{h}}$ current, ZD7288 and $\mathrm{Cs}^{+}$, abolished the voltage sag and rebound depolarization. ZD7288 induced a hyperpolarization concomitant with an increase in the membrane input resistance in L-INs and PNs. Voltage-clamp recordings revealed $\mathrm{I}_{\mathrm{h}}$ as slowly activating inward current with a reversal potential close to $-50 \mathrm{mV}$ and a mid-activation point around $-90 \mathrm{mV}$. Both, ZD7288 (1-10 $\mu \mathrm{M})$ and $\mathrm{Cs}^{+}(1-2$ $\mathrm{mM}$ ) reduced $\mathrm{SBA}$, spontaneous activity-driven $\mathrm{Ca}^{2+}$ transients, and frequency as well as amplitude of miniature GABAergic postsynaptic currents. Immunocytochemistry and Western blot demonstrated that HCN1 and HCN2 were the prevalent isoforms of HCN channels expressed in L-INs and PNs. These results suggest an important contribution of $\mathrm{HCN}$ channels to the maintenance of SBA in embryonic cortical cultures.

Copyright $\odot 2011$ S. Karger AG, Basel
\end{abstract}

\section{Introduction}

Synchronized spontaneous burst activity of developing cortical networks has been observed in vivo, in isolated neocortical slices and in primary culture [1-3]. The underlying mechanisms, however, are still elusive. It has been proposed that SBA in cortical networks may be due to activity-dependent changes in the balance of excitation and inhibition $[1,4]$. Alternatively, neurons could have intrinsic mechanisms that potentially can generate pacemaker activity $[5,6]$. Among potential mechanisms, the $\mathrm{I}_{\mathrm{h}}$ current provides a depolarizing current upon hyperpolarization, thereby shaping patterns of rhythmic action potential discharge [7]. Moreover, $\mathrm{I}_{\mathrm{h}}$ has been shown to contribute to the resting potential, presynaptically facilitates neurotransmitter release and regulates shaping of synaptic potentials during dendritic integration [8-11].

As a hallmark of $\mathrm{I}_{h}$ current, a voltage sag upon hyperpolarizing current injections has been observed in various types of neurons [12-14]. The presence of $I_{h}$ current has also been documented for putative GFP-positive interneurons in subcoeruleus and pontine nucleus oralis of GAD67 knock-in mice [15]. The ion channels mediating $\mathrm{I}_{\mathrm{h}}$ currents are the hyperpolarization-activated cyclic nucleotide-gated cation (HCN) channels. Expression of

J.K. and A.D. de L. are equally contributing first authors.

\section{KARGER}

Fax +41613061234 E-Mail karger@karger.ch www.karger.com
Dr. Thomas Munsch

Otto-von-Guericke Universität, Medizinische Fakultät, Institut für Physiologie Leipziger Strasse 44

DE-39120 Magdeburg (Germany)

Tel.+49 391671 3676, E-Mail thomas.munsch@med.ovgu.de 
HCN1 channels as early as the first postnatal week critically contributes to giant depolarizing potentials (GDPs) in the developing rat hippocampus [14]. In this preparation, interneuronal HCN channels have been shown to either generate a depolarizing drive or synchronize firing of principal neurons $[12,16]$ and determine the integrative properties of fast-spiking basket interneurons [17].

The reports of SBA in cortical preparations [1-3] point to a comparable role of $\mathrm{I}_{\mathrm{h}}$ in cortical development and prompted us to examine whether $\mathrm{I}_{\mathrm{h}}$ current is present in cultured embryonic cortical interneurons and PNs of GAD67-GFP mice, and to characterize its properties. Subsequently, we attempted to answer the question whether $\mathrm{I}_{\mathrm{h}}$ current contributes to shaping of SBA, and which isoforms of HCN channels are expressed in cultured cortical neurons. We found that HCN channels are functionally expressed at pre- and postsynaptic locations and may contribute to the shaping and maintenance of SBA in developing cortical cultures.

\section{Materials and Methods}

\section{Cell Culture}

Cortical cultures were prepared from embryonic brains of GAD67-GFP ( $\Delta$ neo) mice (in the following: GAD67-GFP mice [18]). Details of the culture protocol are described previously [19]. Briefly, 3-5 mouse brains (taken at embryonic day 16) emitting green fluorescence were used for every preparation. The dorsal parts of the telencephalic vesicles were dissociated with trypsin/ EDTA and seeded onto the top of a confluent astroglial feeding layer at a density of 1,300 cells/mm ${ }^{2}$ in N2 medium [75\% DMEM, 25\% Ham's F12, N2 supplements (Life Technologies, Karlsruhe, Germany)], supplemented with $20 \mathrm{ng} / \mathrm{ml}$ triiodo-L-thyronine and $0.2 \mu \mathrm{g} / \mathrm{ml}$ corticosterone (Sigma-Aldrich, Germany). Half of the medium was then changed once a week. All cultures were maintained at $36^{\circ} \mathrm{C}$ in a humidified atmosphere $\left(95 \%\right.$ air and $\left.5 \% \mathrm{CO}_{2}\right)$. Most characterizations were performed on mature cultures at 12 29 days in vitro (DIV), unless stated otherwise.

Astroglial subcultures were prepared from cortex of P0 to P2 C57/B6 mice, plated at a density of 500 cells $/ \mathrm{mm}^{2}$ and cultivated to confluent monolayer for one week before plating of neurons.

All experimental procedures were approved by local government (Landesverwaltungsamt Halle, Germany).

\section{Immunocytochemistry}

For immunocytochemical double staining of HCN 1-4 channel isoforms and GFP, cell cultures were first fixed for $30 \mathrm{~min}$ at $36^{\circ} \mathrm{C}$ in $4 \%$ paraformaldehyde in phosphate buffer (PFA, $0.1 \mathrm{M}$, $\mathrm{pH}$ 7.4). After washing with PBS (0.01 M, pH 7.4), cultures were briefly exposed to ice-cold methanol and then incubated in $0.25 \%$ Triton X-100, 10\% goat serum, $5 \%$ sucrose and $2 \%$ BSA in PBS for $15 \mathrm{~min}$ at $4^{\circ} \mathrm{C}$. Cultures were then incubated overnight with one of the following rabbit polyclonal antibodies: anti-HCN1, antiHCN2, anti-HCN3 and anti-HCN4 (Alomone Labs, Jerusalem, Israel; 1:400). HCN antibody binding was visualized with a sec- ondary antibody (goat anti-rabbit indocarbocyanine 3 (Cy3), 1:400; Dianova, Hamburg, Germany). In control experiments, each primary antibody was preincubated with control peptide antigen (1:1) for $1 \mathrm{~h}$ at room temperature, and no specific immunofluorescence for the preincubated antibodies was detected. After the second fixation, cultures were stained for GFP (monoclonal anti-GFP 1:100; Molecular Probes, Goettingen, Germany). The secondary antibody used was goat anti-mouse indocarbocyanine 2 (Cy2, 1:400; Dianova). Cultures were mounted with fluoromount (Serva, Heidelberg, Germany) for further fluorescence microscopy.

Colocalization of HCN1-4 channels with GFP was analysed in randomly chosen fields from three to seven coverslips from 2-4 preparations. Images were taken on an upright epifluorescence microscope equipped with a CCD camera (Axiophot; Zeiss, Oberkochen, Germany). At each position, one image was taken with a filter set optimized for Cy2, the second image was taken with a filter set optimized for $\mathrm{Cy} 3$ and the third was a DIC image. Images were then superimposed in MetaMorph software (version 6.01; Universal Imaging Corp., West Chester, Pa., USA). No contrast or brightness correction was used.

Western Blot

Protein was extracted from cultured neurons according to standard procedures using RIPA-Lysis-Buffer [50 mM Tris, $\mathrm{pH}$ 8.0, $150 \mathrm{mM} \mathrm{NaCl}, 1 \%$ Igepal, $0.5 \%$ deoxycholate, $0.1 \%$ SDS, $10 \%$ glycerol, $1 \mathrm{~mm}$ PMSF, $4 \%$ protease inhibitor cocktail (Complete, Roche), $4^{\circ} \mathrm{C}$. Protein concentration was determined by the bicinchoninic acid assay (BCA, Pierce, Thermo Scientific). Equal amounts of protein homogenate were separated on SDS-PAGE (10-20 $\mu \mathrm{g}$ per lane) and transferred to nitrocellulose membranes (Optitran BA-S; Schleicher \& Schuell). Membranes were blocked with $5 \%$ non-fat dry milk, $1 \%$ normal goat serum in PBS-Tween $20(0.1 \%)$ for $1 \mathrm{~h}$ and incubated in primary antibody [HCN1 1:200, HCN2 1:300 (Alomone Labs), GAPDH $1 \mu \mathrm{g} / \mathrm{ml}$ (Covance, Berkeley, Calif., USA) or $\beta$-actin $0.5 \mu \mathrm{l} / \mathrm{ml}$ (Sigma)], dissolved in $1 \%$ non-fat dry milk, 1\% normal goat serum in PBS-Tween 20 (0.1\%). Blots were then washed $3 \times 10 \mathrm{~min}$ in PBS-Tween $20(0.1 \%)$ and placed in HRP-conjugated anti-rabbit secondary antibody (1:2,000 for HCN1 and HCN2; DAKOcytomation, Hamburg, Germany) or HRP-conjugated anti-mouse antibody (1:10,000 for $\beta$-actin and GAPDH; DAKOcytomation). After the final washes (three times in PBST), the immunoreactive bands were visualized using Super-Signal West Dura (Thermo Scientific) reagents and captured by Gene Gnome, using Gene Snap Software (Syngene). Digital images were quantified using MetaMorph software. To determine both HCN1 and HCN2 amounts in the same gels, the nitrocellulose blots were stripped (Restore ${ }^{\mathrm{TM}}$ Western Blot Stripping Buffer; Thermo Scientific), after images were taken from the first reaction (either $\mathrm{HCN} 1$ or $\mathrm{HCN} 2$ ), re-probed for the second antibody, and quantified again as described above. Optical densities for bands were determined relative to baseline values immediately above or below the bands in the same lanes. The HCN protein bands were normalized to the actin bands, which served as controls for loading equivalence. For display purposes, the normalized levels were then expressed as a fraction of the mean values of all lanes in single gels. Data were taken from gels of 4 independent developmental series, each derived from one preparation. Whole protein extracts from 5 sister cultures were pooled for each age and experiment. Statistical significance of differences 
among different ages was tested with one-way ANOVA or ANOVA on Ranks (Sigma Stat, version 3.5; Systat Software, Inc., Chicago, Ill., USA).

\section{Electrophysiology}

An acrylic insert was glued to the culture dish with silicon resulting in a recording chamber with a volume of 1-1.5 $\mathrm{ml}$. The chamber was mounted on the stage of an inverted microscope and constantly perfused with ACSF at $1.5-2 \mathrm{ml} / \mathrm{min}$. All recordings were performed at $27-29^{\circ} \mathrm{C}$. Whole-cell current-clamp and voltage-clamp recordings were obtained using a patch-clamp amplifier (EPC-7; HEKA Elektronik, Lambrecht/Pfalz, Germany). Patch pipettes were pulled from borosilicate glass (GC150TF-10; Harvard Apparatus Ltd., London, UK) with tip resistances of 2.5$4 \mathrm{M} \Omega$. Characterization of basic properties of $\mathrm{I}_{h}$ and the effects of $\mathrm{I}_{\mathrm{h}}$ blockers were performed with the following pipette solution (in $\mathrm{mM}$ ): 95 potassium gluconate, 20 potassium citrate, $10 \mathrm{NaCl}$, $1 \mathrm{MgCl}_{2}, 0.5 \mathrm{CaCl}_{2}, 10$ HEPES, 3 potassium BAPTA, $3 \mathrm{Mg}$-ATP, $0.5 \mathrm{Na}-\mathrm{GTP}$. The resting membrane potential was measured directly after establishment of the whole-cell configuration, and then sets of hyper- and depolarizing currents were applied from a potential of $-60 \mathrm{mV}$. The resting membrane potential, input resistance, rebound depolarization and sag amplitude were measured in the presence of antagonists of glutamate receptors 6-cyano-7-nitroquinoxaline-2,3-dione disodium salt (CNQX, $5 \mu \mathrm{M}$ ) and D-2-amino-5-phosphonopentanoic acid (APV, $12.5 \mu \mathrm{M}$; Tocris, Bristol, UK) and antagonist of $\mathrm{GABA}_{\mathrm{A}}$ receptors $(10 \mu \mathrm{M}$ bicuculline methiodide (BMI), Tocris) to block SBA.

Spontaneous and miniature PSCs were recorded with a pipette solution containing (in $\mathrm{mM}$ ): 117 caesium gluconate, $13 \mathrm{CsCl}$, $1 \mathrm{MgCl}_{2}, 0.07 \mathrm{CaCl}_{2}, 10 \mathrm{HEPES}, 0.1$ EGTA, $3 \mathrm{Mg}$-ATP, $0.5 \mathrm{Na}-$ GTP. Quantitative analysis of $\mathrm{I}_{\mathrm{h}}$ was performed by digital subtraction of traces in the absence and presence of $30 \mu \mathrm{M}$ ZD7288 (Tocris) or $1 \mathrm{mM} \mathrm{CsCl}\left(\mathrm{Cs}^{+}\right)$. All measurements were corrected for a liquid junction potential of $10 \mathrm{mV}$. The fully activated current versus voltage $(\mathrm{I}-\mathrm{V})$ relationship was obtained by a test pulse to $-120 \mathrm{mV}$ (duration 1,200 ms) followed by steps to different test potentials from -60 to $-110 \mathrm{mV}$ in $5-\mathrm{mV}$ increments. The recorded tail current amplitudes, measured $50 \mathrm{~ms}$ after the beginning of test pulse, were plotted against each test potential to construct the fully activated I-V. The reversal potential was extrapolated by linear regression. The steady-state activation curve of $\mathrm{I}_{\mathrm{h}}$ was measured by stepping from a holding potential of -50 to $-130 \mathrm{mV}$ in $10-\mathrm{mV}$ increments for $800-2,200 \mathrm{~ms}$ followed by a repolarizing step to $-60 \mathrm{mV}$ (fig. 2b). To increase the stability of whole-cell recordings with increasing hyperpolarization, pulse duration was decreased in each step by $200 \mathrm{~ms}$. Steady-state activation of $\mathrm{I}_{\mathrm{h}}$ was constructed by normalizing the tail current amplitudes, $50 \mathrm{~ms}$ after onset of tail currents, using the following equation $\mathrm{p}(\mathrm{O})=$ $\left(\mathrm{I}-\mathrm{I}_{\min }\right) /\left(\mathrm{I}_{\max }-\mathrm{I}_{\min }\right)$, with $\mathrm{I}_{\max }$ - current amplitude for the voltage step at $-130 \mathrm{mV}$. The resulting data were fitted by a Boltzmann function of the form:

$$
\mathrm{P}(\mathrm{O})=\left[1+\exp \left(\left(\mathrm{V}_{\mathrm{m}}-\mathrm{V}_{1 / 2}\right) / \kappa\right)\right]^{-1},
$$

from which the values of half-maximal activation $\left(\mathrm{V}_{1 / 2}\right)$ and the slope factor (к) were obtained.

GABAergic PSCs were recorded at a holding potential of $0 \mathrm{mV}$ as outwardly directed currents in the presence of glutamate receptor antagonists APV $(12.5 \mu \mathrm{M})$ and CNQX $(5 \mu \mathrm{M})$. Miniature GABAergic postsynaptic currents (mGABAPSCs) were recorded in the presence of $1 \mu \mathrm{M}$ TTX (Tocris). Signals were identified as GABAergic currents by block with BMI $(10 \mu \mathrm{M})$ at the end of some experiments $(n=3)$. Glutamatergic sPSCs were recorded at a holding potential of $-60 \mathrm{mV}$ as inwardly directed currents. All drugs were bath-applied. Detection of synaptic currents with subsequent analysis was performed using MiniAnalysis software (version 6.0.3; Synaptosoft, Inc., Decatur, Ga., USA).

Data were filtered at $3 \mathrm{kHz}$ and sampled at $6.3 \mathrm{kHz}$ in current clamp experiments and at $3.2-5 \mathrm{kHz}$ in voltage clamp experiments using Pulse software (v8.77; HEKA Elektronik). Effects of ZD7288 and $\mathrm{Cs}^{+}$were measured 5-10 min after application of the substance.

All data are expressed as means \pm SEM. Statistical significance of differences before and after application of ZD7288 or Cs ${ }^{+}$ was tested with the Wilcoxon signed-rank test (Graph Pad Prism 3.02; GraphPad Software Inc., Calif., USA) or with the one-sample $t$ test if the distribution of the data were Gaussian.

\section{Calcium Imaging}

The spontaneous network activity of 13- to 16-day-old mouse cultures was recorded by using Fluo-3 Calcium Indicator (Molecular Probes, Invitrogen). Each culture was incubated with $5 \mu \mathrm{M}$ Fluo-3 for $1 \mathrm{~h}$ followed by several washes with Hepes-buffered Ringer solution (in mM: $140 \mathrm{NaCl}, 5 \mathrm{KCl}, 1.5 \mathrm{CaCl}_{2}, 0.75 \mathrm{MgCl}_{2}$, $1.25 \mathrm{NaH}_{2} \mathrm{PO}_{4}, 20$ D-glucose, 15 Hepes/ $\mathrm{NaOH}, \mathrm{pH}$ 7.4). After 30 min to allow deesterification of the dye, sequences of fluorescence images were recorded at $1 \mathrm{~Hz}$ during 4-min sessions on an inverted microscope (Axiovert; Zeiss, Oberkochen, Germany) equipped with a cooled CCD camera (CoolSNAP ES; Roper Scientific, Germany). The recorded fields (3-5 for each culture dish) were chosen randomly and marked with a diamond tool for repeated measurements. A differential interference contrast (DIC) image of each field was acquired before imaging for later identification of cells. Images were processed with MetaMorph software (version 7.0; Molecular Devices, Sunnyvale, Calif., USA). A change in $\left[\mathrm{Ca}^{2+}\right]_{\mathrm{i}}$ was considered significant when the absolute difference of grey values exceeded five times the standard deviation of background noise measured in cell-free areas [20]. Fluorescence data are expressed as $\Delta \mathrm{F} / \mathrm{F}_{0}$ (background-corrected increase in fluorescence divided by resting fluorescence). Attendance is used throughout in terms of participating cells in a given frame as percent of all active cells. The analysis of the calcium activity was performed with custom-made software written in MATLAB (version 7.5; MathWorks, Natick, Mass., USA) and Excel (Microsoft Corp., Richmond, Wash., USA). Statistical tests were perfomed using SigmaStat (version 2.03, SPSS Inc., Chicago, Ill., USA).

\section{Results}

Effects of ZD7288 and $\mathrm{Cs}^{+}$on Membrane Properties of Cultured Cortical Neurons

During injection of hyperpolarizing current pulses $(-80$ to $-150 \mathrm{pA})$, a distinct voltage sag and rebound depolarization $(\mathrm{RD})$ were observed in all recorded L-INs $(\mathrm{n}=6$; fig. 1a) and PNs ( $\mathrm{n}=11$; fig. 1b). ZD7288 (30 $\mu \mathrm{M})$ 


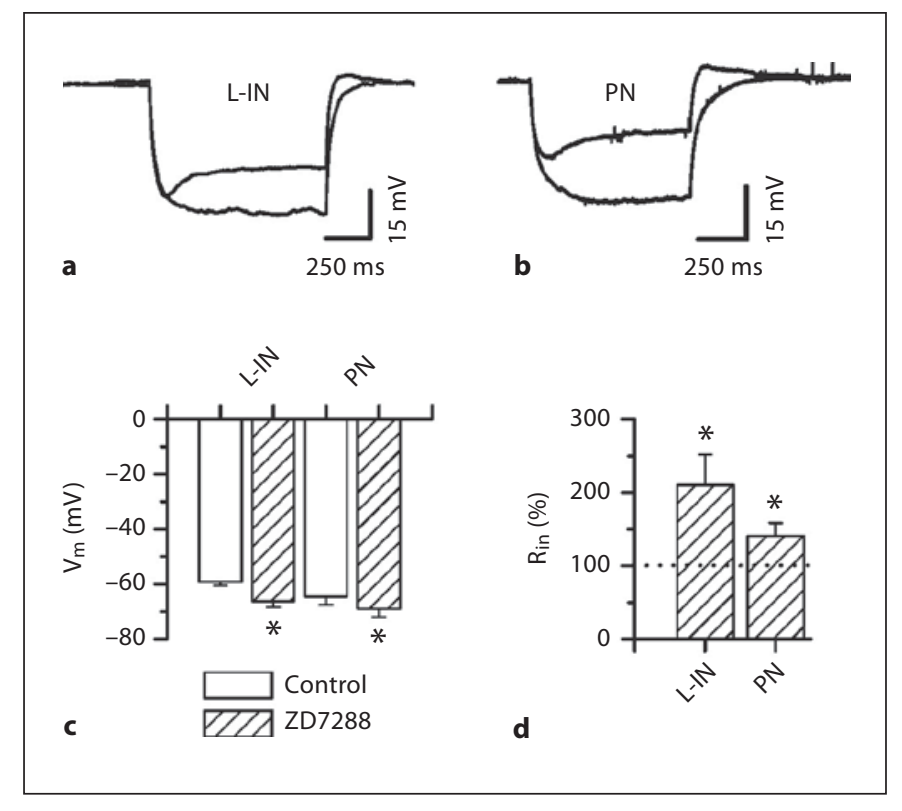

Fig. 1. Effects of ZD7288 on passive membrane properties of LINs (interneurons) and PNs (projection neurons) in mature (1229 DIV) mouse cortical cultures. a, b Voltage traces recorded in a L-IN (a) and a PN (b) during hyperpolarizing current step (-80 and $-100 \mathrm{pA}$, respectively, for $1 \mathrm{~s}$ ) under control conditions and in the presence of $30 \mu \mathrm{M} Z \mathrm{ZD} 7288$. Note the block of the voltage sag and the rebound depolarization by ZD7288. c, d Summary bar graphs of the effects of $30 \mu \mathrm{M} Z \mathrm{ZD} 7288$ on resting membrane potential (c) and normalized input resistance (d) in mature cortical cultures. Dotted line in $\mathbf{d}$ represents control. Values are means \pm SEM; ${ }^{*} \mathrm{p}<0.05$.

completely abolished the voltage sag and the rebound depolarization in L-INs $(n=6)$ and PNs $(n=9$; fig. 1a, b). Another antagonist of $\mathrm{HCN}$ channels, $\mathrm{Cs}^{+}(1 \mathrm{mM})$, showed similar effects, abolishing the voltage sag and the rebound depolarization in 5 of 6 tested L-INs and in 3 of 3 tested PNs. ZD7288 led to a distinct hyperpolarization of the L-INs by $6.8 \pm 1.6 \mathrm{mV}(\mathrm{n}=6, \mathrm{p}<0.05)$ and $4.3 \pm$ $1.1 \mathrm{mV}$ by PNs $(\mathrm{n}=9, \mathrm{p}<0.05$; fig. 1c). Correlated with the marked hyperpolarization induced by ZD7288, the somatic input resistance $\left(\mathrm{R}_{\mathrm{in}}\right)$, measured at the end of a hyperpolarizing current pulse, increased to $210.2 \pm$ $41.7 \%$ in L-INs $(\mathrm{n}=5, \mathrm{p}<0.05)$ and to $140.8 \pm 17.4 \%$ in PNs ( $n=7, p<0.05$; fig. 1d). Effects of ZD7288 and Cs ${ }^{+}$ were observed already 3-5 min after the onset of application. This confirms recent observations [13] that HCN channels as a conductor of $\mathrm{I}_{\mathrm{h}}$ current are widely expressed in acute slices of mouse cerebral cortex at 12-29 DIV.

\section{Kinetic Properties of $I_{h}$ Current in Cultured Cortical} Neurons

Using the voltage-clamp mode, we next examined the reversal potential and half-maximal activation of $\mathrm{I}_{\mathrm{h}}$ currents in L-INs and PNs. $\mathrm{I}_{\mathrm{h}}$ current was isolated by subtracting current traces in the presence of $1 \mathrm{mM} \mathrm{Cs}^{+}$from those under control conditions. To determine the reversal potential, $\mathrm{I}_{\mathrm{h}}$ current was activated by a hyperpolarizing prepulse to $-120 \mathrm{mV}$ from a holding potential of $-50 \mathrm{mV}$ and measured $50 \mathrm{~ms}$ after the beginning of the test pulse to potentials between -110 and $-60 \mathrm{mV}$ for L-INs or -120 to $-10 \mathrm{mV}$ for PNs, respectively (fig. 2a). Instantaneous currents were plotted against the test potential. The reversal potential $\left(\mathrm{E}_{\text {rev }}\right)$ was analyzed by estimating the point of intersection of a linear regression line with the voltage axis. $\mathrm{E}_{\mathrm{rev}}$ amounted to $-48.4 \pm 2.1 \mathrm{mV}$ for L-INs $(\mathrm{n}=15$; fig. $2 \mathrm{c}$ ) and $-45.7 \pm 2.6 \mathrm{mV}$ for PNs ( $\mathrm{n}=5$; fig. $2 \mathrm{e}$ ).

To determine the steady-state activation curve of $\mathrm{I}_{\mathrm{h}}$, tail currents were measured $50 \mathrm{~ms}$ after repolarizing the membrane to $-60 \mathrm{mV}$ following voltage steps to potentials between -50 and $-130 \mathrm{mV}$ (fig. $2 \mathrm{~b}$ ). To minimize the time used to clamp the membrane potential at very negative potentials, we decreased step duration with increasing hyperpolarization. Fitting the data with a Boltzmann function revealed half-maximal activation of $\mathrm{I}_{\mathrm{h}}$ in L-INs of $-94.2 \pm 0.9 \mathrm{mV}(\mathrm{n}=15$; fig. $2 \mathrm{~d})$ and $-89.5 \pm 0.9 \mathrm{mV}$ in PNs ( $\mathrm{n}=5$; fig. $2 \mathrm{f})$.

\section{Blockade of $I_{h}$ Impairs SBA in Cortical Cultures}

As has been previously shown, $\mathrm{I}_{\mathrm{h}}$ contributes to the occurrence of developmentally relevant spontaneous activity in the immature cortex in vitro [13]. This prompted us to study the functional role of $\mathrm{I}_{\mathrm{h}}$ in generation and maintenance of SBA in mouse cortical cultures. Spontaneous bursts were recorded under current-clamp conditions from PNs in cortical cultures as early as 5-7 DIV (data not shown). The effects of ZD7288 and $\mathrm{Cs}^{+}$on network activity were examined in mature cultures, characterized by a frequency of spontaneous bursts of $0.16 \pm 0.05 \mathrm{~Hz}$ (fig. 3a, c; online supplementary fig. 1, available at www. karger.com/doi/10.1159/000330813). ZD7288 at a concentration of $1 \mu \mathrm{M}$ led to a significant decrease $(\mathrm{p}<0.05)$ of burst frequency to $0.09 \pm 0.04 \mathrm{~Hz}, 5 \mathrm{~min}$ after application ( $n=6$; fig. 3b, c). Increasing concentrations of ZD7288 further reduced the frequency of spontaneous bursts in all recorded PNs $(10 \mu \mathrm{M} Z \mathrm{ZD} 7288: 0.05 \pm 0.02 \mathrm{~Hz} ; 30 \mu \mathrm{M}$ ZD7288: $0.04 \pm 0.02 \mathrm{~Hz} ; \mathrm{n}=6$; fig. $3 \mathrm{c}$, d). To rule out that ZD7288 exerts its effects on burst frequency by directly blocking AMPA-type glutamate receptors [21], we repeated this experiment with $1 \mathrm{mM} \mathrm{Cs}^{+}$. Shortly after applica- 
tion, $\mathrm{Cs}^{+}$showed similar effectiveness in reducing burst frequency to $23.2 \pm 4.0 \%(\mathrm{n}=4, \mathrm{p}<0.05$; online suppl. fig. 1b). Prolonged exposure to $1 \mathrm{mM} \mathrm{Cs}^{+}$, however, disrupted oscillatory activity so that it became difficult to quantify a characteristic oscillation frequency (online suppl. fig. 1c).

Additionally, we examined the effect of ZD7288 on spontaneous glutamatergic postsynaptic currents (sGluPSCs) recorded in five projection neurons (PNs). At the concentration used $(30 \mu \mathrm{M}), \mathrm{ZD} 7288 \mathrm{did}$ not significantly $(p>0.05)$ affect the frequency or the amplitude of sGluPSCs. Mean frequency amounted to $85.7 \pm$ $8.0 \%(\mathrm{n}=5)$ and mean amplitude to $107.6 \pm 5.9 \%(\mathrm{n}=$ 5) of control values (fig. 3e), confirming the absence of a direct effect of $30 \mu \mathrm{M}$ ZD7288 on glutamatergic transmission.

Spontaneous network activity was also investigated by means of calcium imaging (fig. 4). The frequency of spontaneous calcium transients and the proportion of cells actively participating in a single transient were calculated before and after acute application of 1-30 $\mu \mathrm{M}$ ZD7288 or 1-2 $\mathrm{mM} \mathrm{Cs}^{+}$. Overall, the cultures, which were examined between 13 and 16 DIV ( $n=12$, from two experiments), showed spontaneous transients with a frequency range between 4 and 12.5 transients/min $(8.28 \pm 0.38$ transients/min; fig. $4 \mathrm{a}-\mathrm{d})$. Between 64 and $96 \%$ of all active neurons participated in single synchronous events (attendance: $82.2 \pm 2.3 \%$ ).

ZD7288 decreased spontaneous network activity in a dose-dependent manner (fig. 4a-d), but did not alter attendance during synchronous events $(\mathrm{p}=0.4$, one-way ANOVA; fig. 4g, grey columns). The number of active neurons did not change with $1 \mu \mathrm{M} Z \mathrm{ZD} 7288(\mathrm{p}=0.261)$ or $10 \mu \mathrm{M}$ ZD7288 ( $\mathrm{p}=0.075)$ but decreased with higher concentrations of ZD7288 (30 $\mu \mathrm{M}: \mathrm{p}<0.001$; fig. 4g, black columns). A total of 1,766 active neurons were examined in 12 cultures.

Prolonged treatment with $\mathrm{Cs}^{+}(>30 \mathrm{~min})$ dramatically reduced or completely blocked all calcium transients. Only results of recordings made within 10-30 min after drug application were considered here. Overall, after $\mathrm{Cs}^{+}$ application the frequency was significantly decreased (6 cultures of 14-16 DIV from 2 experiments). However, the frequency of transients in single fields of 2 cultures was either increased or decreased. The increase in frequency was mostly due to the appearance of intra-burst transients of low-amplitude riding on top of the prolonged calcium transients. $\mathrm{Cs}^{+}$significantly decreased the attendance of neurons in single transients (fig. 4h, grey columns). The overall number of active cells was not altered

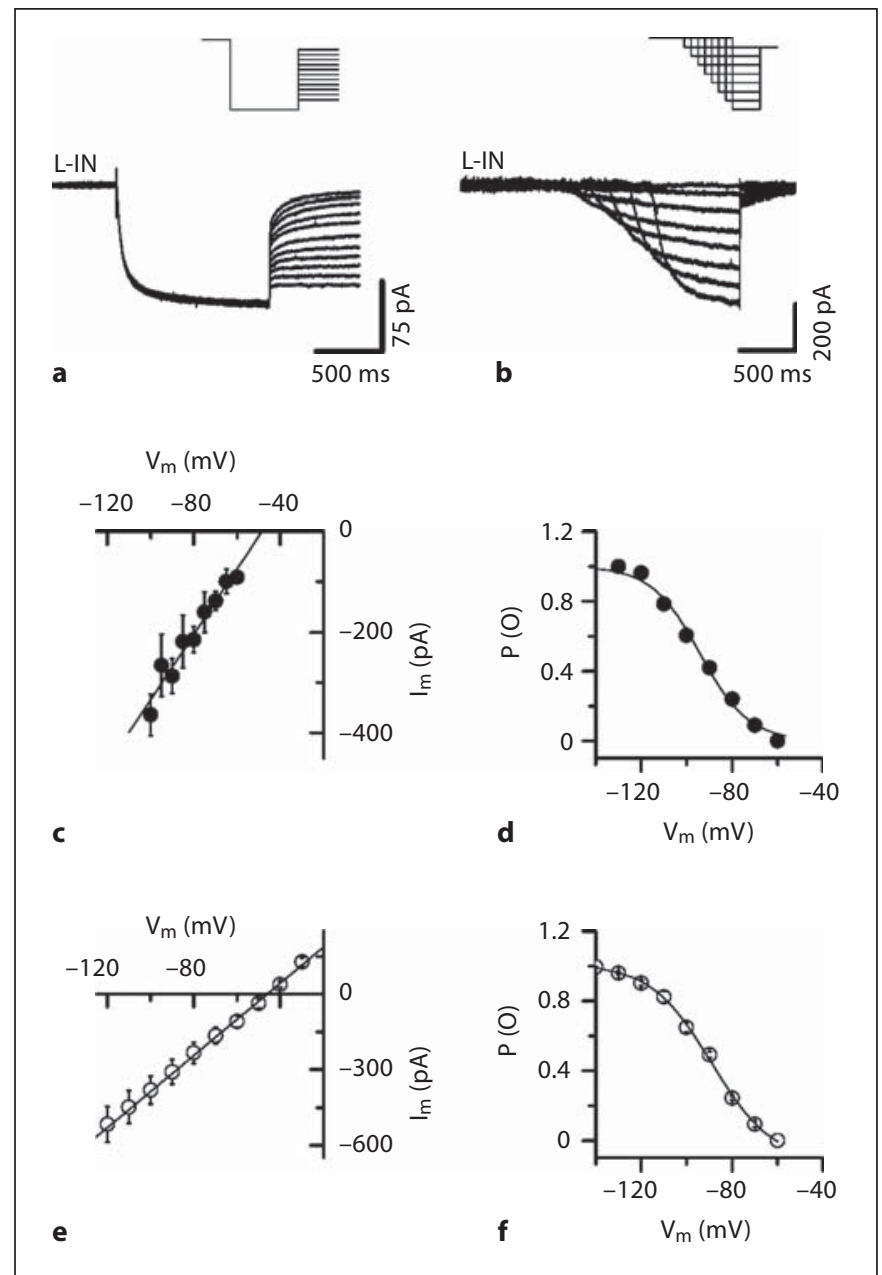

Fig. 2. Basic characteristics of $I_{h}$ in L-INs and PNs. a Protocol (upper panel) and traces of membrane currents (lower panel) activated by a hyperpolarizing prepulse to $-120 \mathrm{mV}$, followed by a test pulse to potentials between -60 and -110 for a representative L-IN (DIV 13). b Protocol (upper panel) and traces of $\mathrm{Cs}^{+}$-sensitive currents (lower panel) activated by a hyperpolarizing test pulse to potentials between -60 and $-130 \mathrm{mV}$ and measured as tail currents by repolarization of the membrane to a fixed potential of -60 $\mathrm{mV}$ in a DIV $13 \mathrm{~L}-\mathrm{IN}$. c Instantaneous current-voltage relationship (I-V) obtained by plotting the current $50 \mathrm{~ms}$ after the onset of the test pulse against test pulse potential. Lines are obtained by linear regression. The extrapolated reversal potential was -48.4 $\pm 2.1 \mathrm{mV}(\mathrm{n}=15)$. $\mathbf{d} \mathrm{I}_{\mathrm{h}}$ channel activation curve of L-INs. $\mathrm{I}_{\mathrm{h}}$ amplitude was measured $50 \mathrm{~ms}$ after stepping to a constant potential $(-60 \mathrm{mV})$ and normalized to the value at $-130 \mathrm{mV}$. Curves are fitted by a Boltzmann function $\left(\mathrm{P}(\mathrm{O})=\left[1+\exp \left(\left(\mathrm{Vm}-\mathrm{V}_{1 / 2}\right) / \kappa\right)\right]^{-1}\right)$. Half-maximal activation was $-94.2 \pm 0.9 \mathrm{mV}(\mathrm{n}=15)$. e Instantaneous current-voltage relationship (I-V) of PNs. The average reversal potential amounted to $-45.7 \pm 2.6 \mathrm{mV}(\mathrm{n}=5)$. $\mathrm{f} \mathrm{h}_{\mathrm{h}}$ channel activation curve of PNs. Half-maximal activation was -89.5 $\pm 0.9 \mathrm{mV}(\mathrm{n}=5)$. 


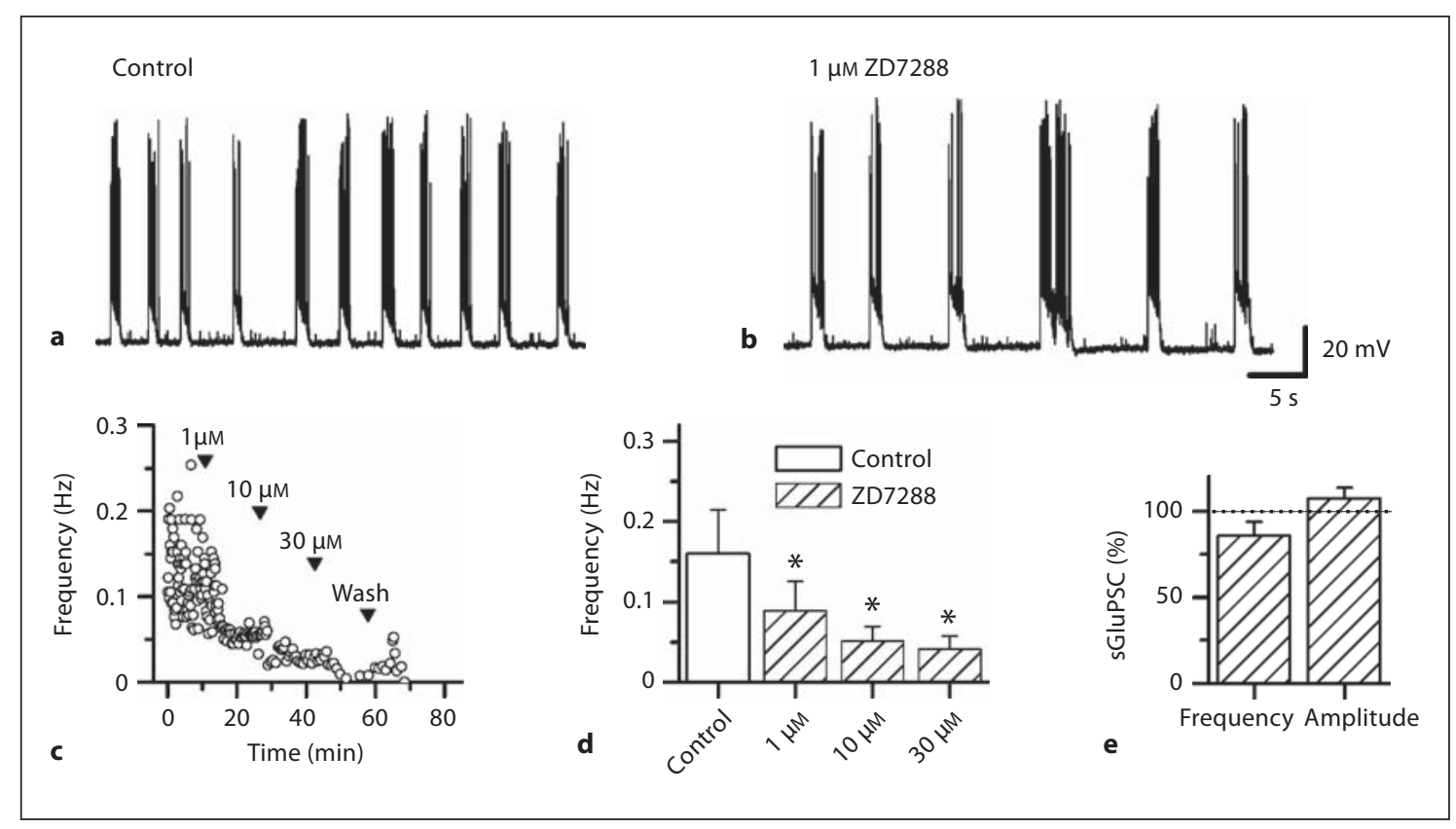

Fig. 3. Effect of ZD7288 on spontaneous burst activity in mature mouse cortical cultures. SBA activity recorded from a PN in a DIV 18 mouse cortical culture. Voltage traces from a continuous current-clamp recording prior to (a) and $10 \mathrm{~min}$ after exposure to $1 \mu \mathrm{M}$ ZD7288 (b). c ZD7288 (1-30 $\mu \mathrm{M})$ gradually attenuates spontaneous burst activity recorded from the same PN. d Summary bar graph of ZD7288 effects on frequency of SBA in mature cultures $(n=6)$. e ZD7288 had no effect on normalized average frequency and amplitude of sGluPSCs recorded from L-INs $(n=5)$. Dotted lines at $100 \%$ represent control. Values are means \pm SEM; ${ }^{*} \mathrm{p}<0.05$.

after addition of $1 \mathrm{mM} \mathrm{Cs}^{+}$, but was decreased after $2-\mathrm{mM}$ $\mathrm{Cs}^{+}$treatment (fig. 4h, black columns).

GAD-GFP neurons' spontaneous network activity mirrored the spontaneous activity of non-GABAergic neurons (fig. $4 \mathrm{a}-\mathrm{c}$, e inset). Similarly, the blockade of $\mathrm{I}_{\mathrm{h}}$ reduced activity frequency of this neuronal subpopulation in a dose-dependent manner (fig. $4 \mathrm{a}-\mathrm{c}$, e inset). The number of active GAD-GFP neurons or their attendance in single events was not significantly altered after treatment with ZD7288 ( $\mathrm{p}=0.180$, ANOVA on ranks, $\mathrm{p}=$ 0.892, one-way ANOVA, respectively).

\section{Subcellular Localization}

To define the subcellular localization of $\mathrm{I}_{\mathrm{h}}$, we recorded miniature and spontaneous GABAergic postsynaptic currents from PNs, the major target cells of LINs in mouse cortical cultures. Miniature GABAPSCs (mGABAPSCs) were recorded in a total of 9 PNs by holding PNs at $0 \mathrm{mV}$, in the presence of $1 \mu \mathrm{M}$ TTX, $12.5 \mu \mathrm{M}$ APV and $5 \mu \mathrm{M} C N Q X$ (fig. 5a). Under control conditions, the mean frequency of mGABAPSCs was $0.37 \pm 0.2 \mathrm{~Hz}$ $(\mathrm{n}=9)$ and the mean amplitude was $21.9 \pm 1.5 \mathrm{mV}(\mathrm{n}=$
9). ZD7288 (30 $\mu \mathrm{M})$ reduced the frequency to $81.4 \pm 3.6 \%$ of the control value $(\mathrm{p}<0.05 ; \mathrm{n}=4)$, whereas the amplitude was not significantly affected $(93.9 \pm 3.0 \%$ of the control value, $\mathrm{p}>0.05$; fig. $5 \mathrm{~b})$. $\mathrm{Cs}^{+}(1 \mathrm{mM})$ yielded similar effects on the frequency of mGABAPSCs (53.9 \pm $15.9 \%$ of the control value; $n=5 ; p<0.05$ ), confirming the presynaptic localization of $\mathrm{HCN}$ channels at the LINs. Interestingly, in the presence of $\mathrm{Cs}^{+}$, the amplitude of mGABAPSCs was also reduced to $80.0 \pm 6.5 \%(n=5$; $\mathrm{p}<0.05$; fig. $5 \mathrm{c}$ ), suggesting a potential localization of $\mathrm{HCN}$ channels also at postsynaptic PNs.

To test whether the effect of $I_{h}$ blockers was dependent on synaptic recruitment of L-INs into network activity, we examined spontaneous GABAPSCs (sGABAPSCs) in PNs. Both compounds influenced neither the frequency nor the amplitude of sGABAPSCs (fig. 5d, e). After application of ZD7288, the mean normalized frequency of sGABAPSCs was $120.1 \pm 15.2 \%$ and the amplitude $90.3 \pm 2.9 \%$ of control ( $n=4$; fig. $5 d$ ). In the presence of $\mathrm{Cs}^{+}$, the frequency amounted to 108.4 $\pm 15.8 \%$ and the amplitude to $107.2 \pm 4.8 \%$ of control values $(n=5$; fig. $5 e)$. 
Fig. 4. Decreased spontaneous network activity after $\mathrm{I}_{\mathrm{h}}$ blockade. a-c Calcium transients recorded in 2-week-old networks (a, b DIV 15, c DIV 14) in control Ringer (left side) and after bath application of $1 \mu \mathrm{M}$ ZD7288 or $1 \mathrm{~mm} \mathrm{CsCl}$. Neurons in b were GAD-GFP interneurons in the same network as unlabeled neurons shown in a. d Summary graph shows the effect of increasing concentrations of ZD7288 on the activity of 13- to 16-day-old networks (11 cultures from 2 experiments). e The network activity is significantly decreased (significant changes compared with the anterior bar: $\left.{ }^{* *} \mathrm{p}<0.001,{ }^{*} \mathrm{p}=0.021\right)$. Inset graph shows that the activity of GABAergic neurons decreased in the same way by addition of ZD7288 (control vs. $1 \mu \mathrm{M}$ ZD7288, ${ }^{* *} \mathrm{p}<0.001 ; 1 \mu \mathrm{M} Z \mathrm{ZD}$ vs. $10 \mu \mathrm{M}$ $\left.\mathrm{ZD},{ }^{*} \mathrm{p}=0.042\right)$. f Network activity decreases significantly with addition of 1$2 \mathrm{mMCs}^{+}$. The frequency of network events is not further reduced by $2 \mathrm{mM}$ compared with $1 \mathrm{mM} \mathrm{Cs}^{+}\left({ }^{*} \mathrm{p}=0.021\right) . \mathbf{g}, \mathbf{h}$ Bar graphs show the relative number of active neurons (black bars) and the attendance of active neurons in single events (gray bars) in recordings under $\mathrm{I}_{\mathrm{h}}$ blockade with ZD7288 (g) or $\mathrm{Cs}^{+}(\mathbf{h})$. Contrary to ZD7288, which does not alter attendance to single bursts, $\mathrm{Cs}^{+}$treatment significantly decreases the number of active neurons participating in single bursts (control vs. $1 \mathrm{mM} \mathrm{Cs}^{+}, \mathrm{p}<$ 0.015 ; control vs. $2 \mathrm{mM} \mathrm{Cs}^{+}, \mathrm{p}=0.004$ ). The total number of active neurons decreases in both cases at the higher concentrations (30 $\mu \mathrm{M}$ ZD7288, $\mathrm{p}<0.001 ; 2 \mathrm{mM} \mathrm{Cs}^{+}, \mathrm{p}=$ $0.003)$. Data in $\mathbf{d}-\mathbf{h}$ are normalized to the mean value of control recordings.

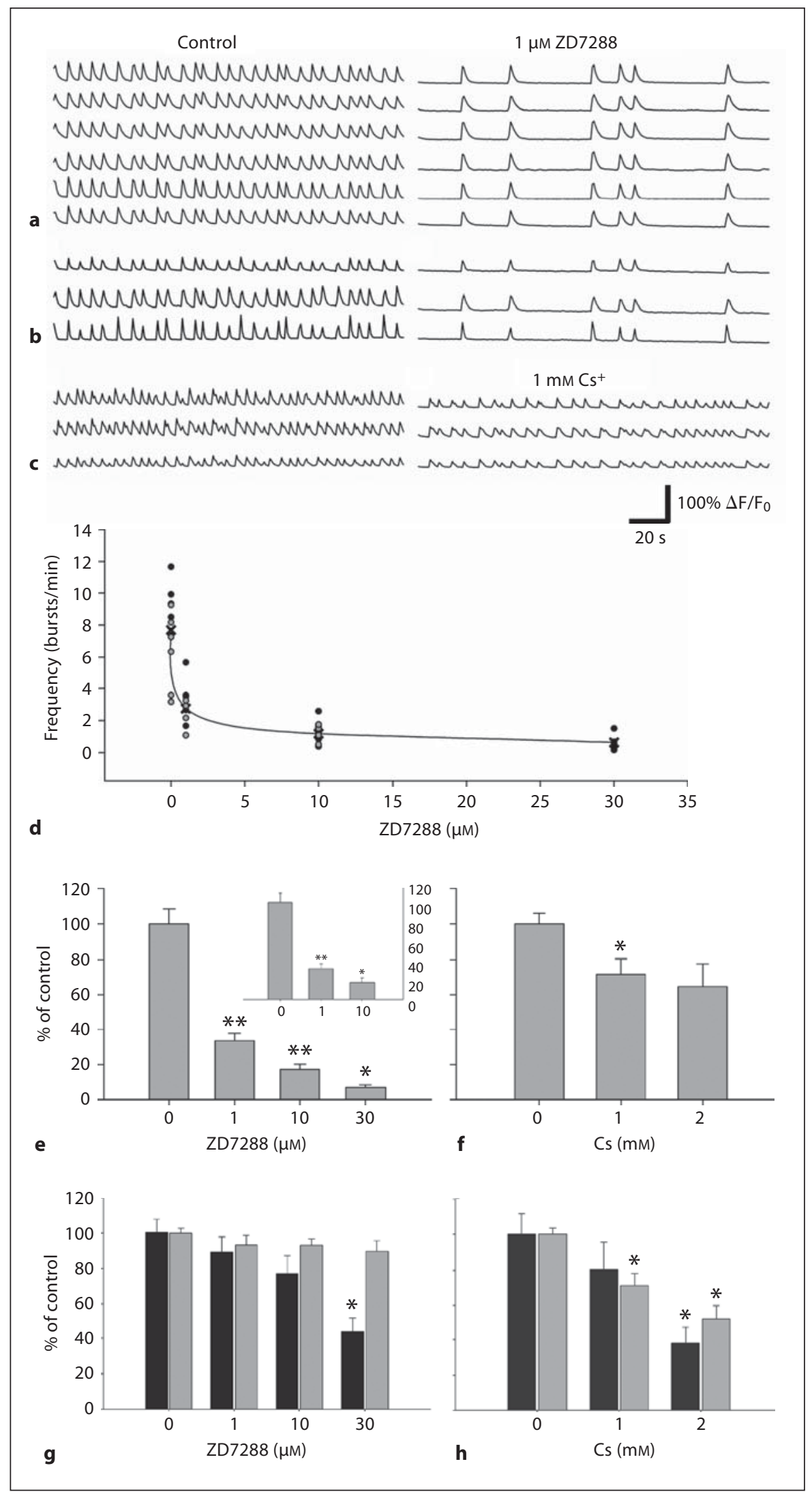


Fig. 5. Effects of ZD7288 and $\mathrm{Cs}^{+}$on miniature and spontaneous GABAergic PSCs. a Miniature GABAPSCs recorded from a $\mathrm{PN}$ at DIV 13. b, c Summary of the effects of $30 \mu \mathrm{M}$ ZD7288 (b; $\mathrm{n}=4)$ and $1 \mathrm{mM} \mathrm{Cs}^{+}$ $(c ; n=5)$ on normalized average frequency and amplitude of mGABAPSCs recorded from PNs. d, e Absence of effects of ZD7288 (d; $\mathrm{n}=4)$ and $\mathrm{Cs}^{+}(\mathbf{e} ; \mathrm{n}=5)$ on normalized average frequency and amplitude of sGABAPSCs recorded from PNs. Dotted lines at $100 \%$ represent control. Values are means \pm SEM; ${ }^{*} \mathrm{p}<0.05$.

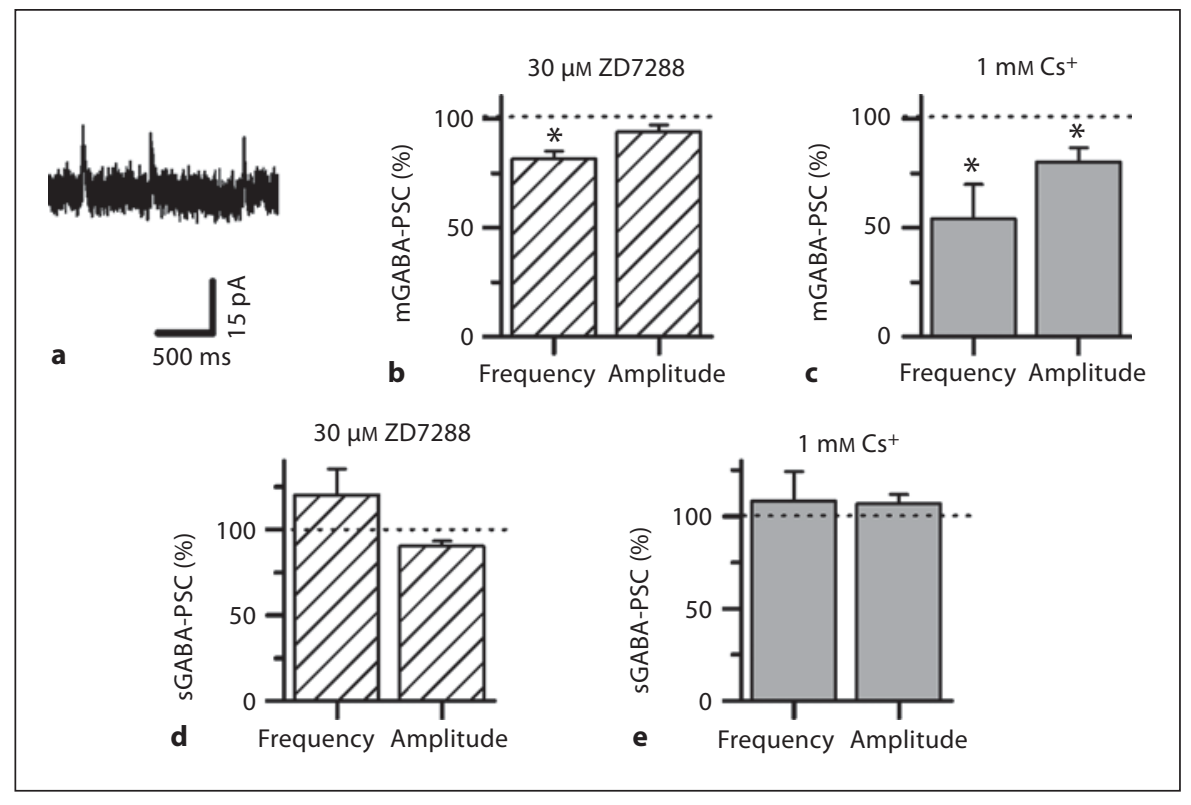

Thus, our results are consistent with a presynaptic localization of HCN channels on the membrane of L-INs and an additional postsynaptic localization in PNs, which both may contribute to the maintenance of SBA in mouse cortical cultures.

\section{Developmental Expression of HCN Subunits}

To examine the development of HCN expression and putative subunit composition of $\mathrm{I}_{\mathrm{h}}$ channels in L-INs and $\mathrm{PNs}$, we analyzed the expression of HCN1-4 isoforms by means of immunocytochemistry (fig. 6) and Western blot (fig. 7). At 6-7 DIV, HCN2 and HCN1 immunoreactivity is conspicuous in cell bodies but also in puncta in neuropile and over dendritic surfaces. Low expression levels of $\mathrm{HCN} 4$ and HCN3 were also detected, mainly on cell bodies. Interestingly, although HCN4 was also expressed in interneurons, most labeled somata were non-GABAergic neurons. At older ages (14-28 DIV), specific immunoreactivity was observed to $\mathrm{HCN} 1$ and $\mathrm{HCN} 2$, but not to $\mathrm{HCN} 3$ and HCN4. Dual labeling of GAD-GFP and HCN1 or $\mathrm{HCN} 2$ revealed overlapping expression predominantly at somatic (fig. 6a-c), but also at dendritic localizations of L-INs at 21 DIV (fig. 6d, e). The colocalization of HCN1 or HCN2 (red puncta) with green dendrites of L-INs is shown at higher magnification in figure $6 \mathrm{~d}$, e. Note that GFP-negative neurons (PNs) also show labeled puncta along somatodendritic surface (fig. $6 \mathrm{f}-\mathrm{h}$, arrow).

Western blots confirmed the expression of HCN1 and $\mathrm{HCN} 2$ subunits in cortical mouse cultures, but failed to detect HCN3 or HCN4. Quantitative Western blot analyses showed that HCN1 and HCN2 isoforms undergo developmental changes in expression levels. A significant increase in $\mathrm{HCN} 1$ and $\mathrm{HCN} 2$ protein levels was detected during the first week in vitro (fig. $7 \mathrm{a}-\mathrm{c}$ ). $\mathrm{HCN} 1$ and $\mathrm{HCN} 2$ protein levels were low at the onset of culturing time, increased significantly between 0 and 7 DIV and showed little change during the second and third weeks in vitro (7-28 DIV) (fig. 7).

\section{Discussion}

In the present study, all L-INs and PNs showed a prominent voltage sag during hyperpolarization, indicating activation of the HCN channels. The slow deactivation kinetics of these channels create a slow depolarization of the membrane [7] which may reach a burst-generating voltage window. Both pharmacological blockade of HCN channels by ZD7288 and $\mathrm{Cs}^{+}$caused a strong reduction of the frequency of SBA. At the relatively low concentrations used in this study, ZD7288 (1$30 \mu \mathrm{M})$ and $\mathrm{Cs}^{+}(1-2 \mathrm{mM})$ had no detectable effects on conductances other than $\mathrm{I}_{\mathrm{h}}$, which have been reported for higher concentrations and long application times [21, 22]. Caesium is frequently referred to as a blocker of $I_{h}$ at low millimolar concentrations [23]. Extracellular $\mathrm{Cs}^{+}$ has been used as a selective blocker of $\mathrm{I}_{\mathrm{h}}$ up to concentrations of $5 \mathrm{~mm}$ in pyloric neurons of the lobster stomato- 

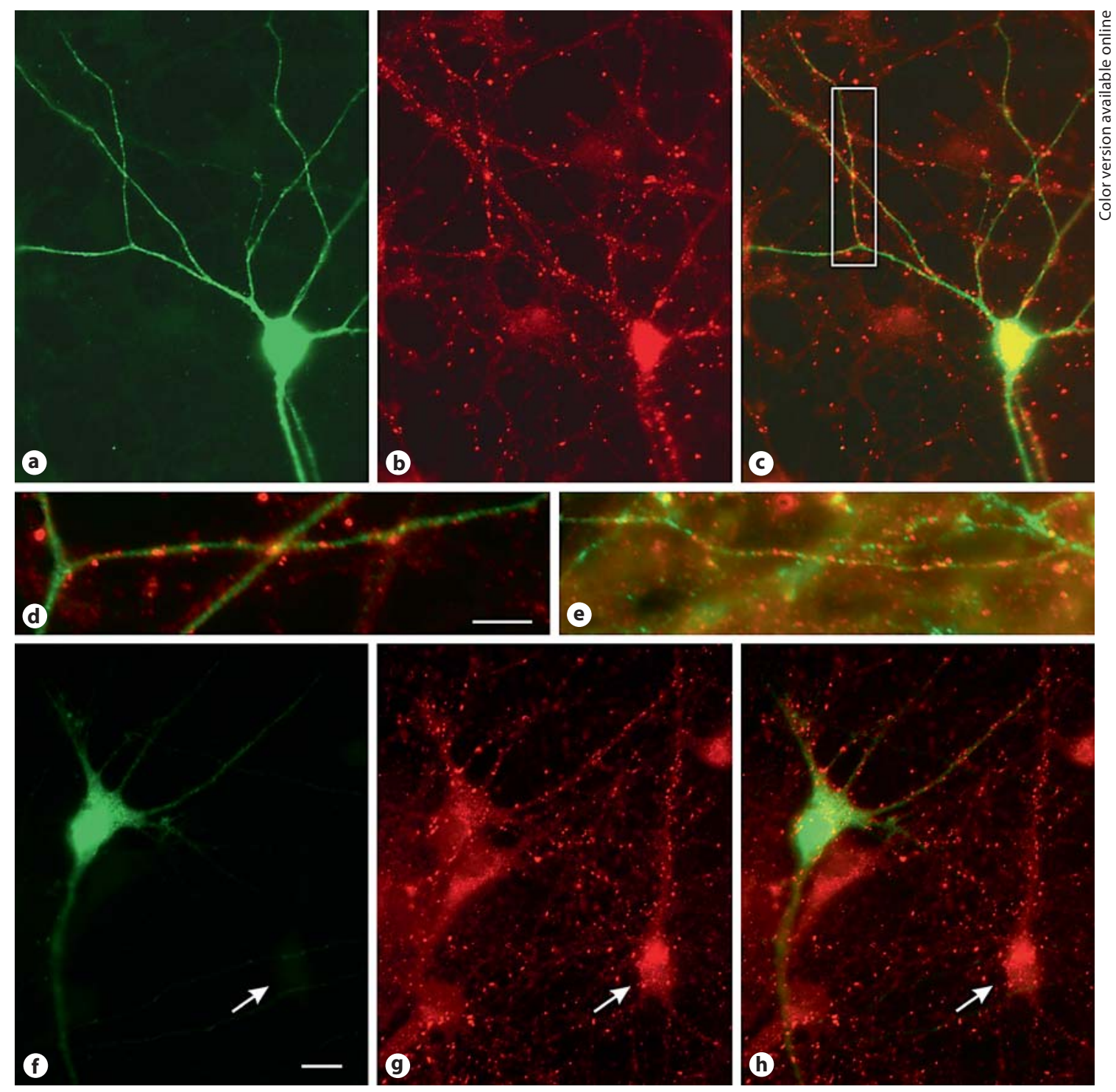

Fig. 6. HCN subunit expression in cortical cultures. a-c Dual labelling of GFP (green) and HCN2 (red) reveals overlapping expression in the soma as well as in the dendrites of L-INs at 21 DIV. d Enlarged image of the boxed region in c. e Merged image of a dual labelling of GFP (green) and HCN1 (red) showing dendritic localization in L-INs at 21 DIV. f-h Dual labelling of GFP (green) and HCN2 (red) reveals overlapping expression in the soma (arrow) as well as in the dendrites of non-GABAergic neurons at 7 DIV. Scale bar for $\mathbf{a}-\mathbf{c}, \mathbf{f}-\mathbf{h}$ shown in $\mathbf{f}=10 \mu \mathrm{m}$; scale bar for $\mathbf{d}$ and e shown in $\mathbf{d}=5 \mu \mathrm{m}$. Colors refer to the online version only.

gastric ganglion, where it does not block other currents at these concentrations [24]. More recently, extracellular $\mathrm{Cs}^{+}$concentrations up to $1 \mathrm{~mm}$ have been shown to decelerate thalamic oscillations due to blockade of $\mathrm{I}_{\mathrm{h}}$ in rat thalamic slices [25]. In slice preparations of the basolateral amygdala of rats, $\mathrm{Cs}^{+}(1 \mathrm{mM})$ was used to selectively block modulation of $\mathrm{I}_{\mathrm{h}}$ by neuropeptides [26]. This does not rule out that other ion channels are affected by ex- tracellular $\mathrm{Cs}^{+}$, as for instance the two-pore domain $\mathrm{K}^{+}$ channel TASK-1 [27], which contributes to the control of activity modes in thalamocortical neurons [28]. The low abundance of TASK-1 in neocortical neurons [29], however, argues against a major contribution of this current to spontaneous burst activity of cortical cultures at the low concentrations (1-2 mM) of extracellular $\mathrm{Cs}^{+}$used in the present study. 


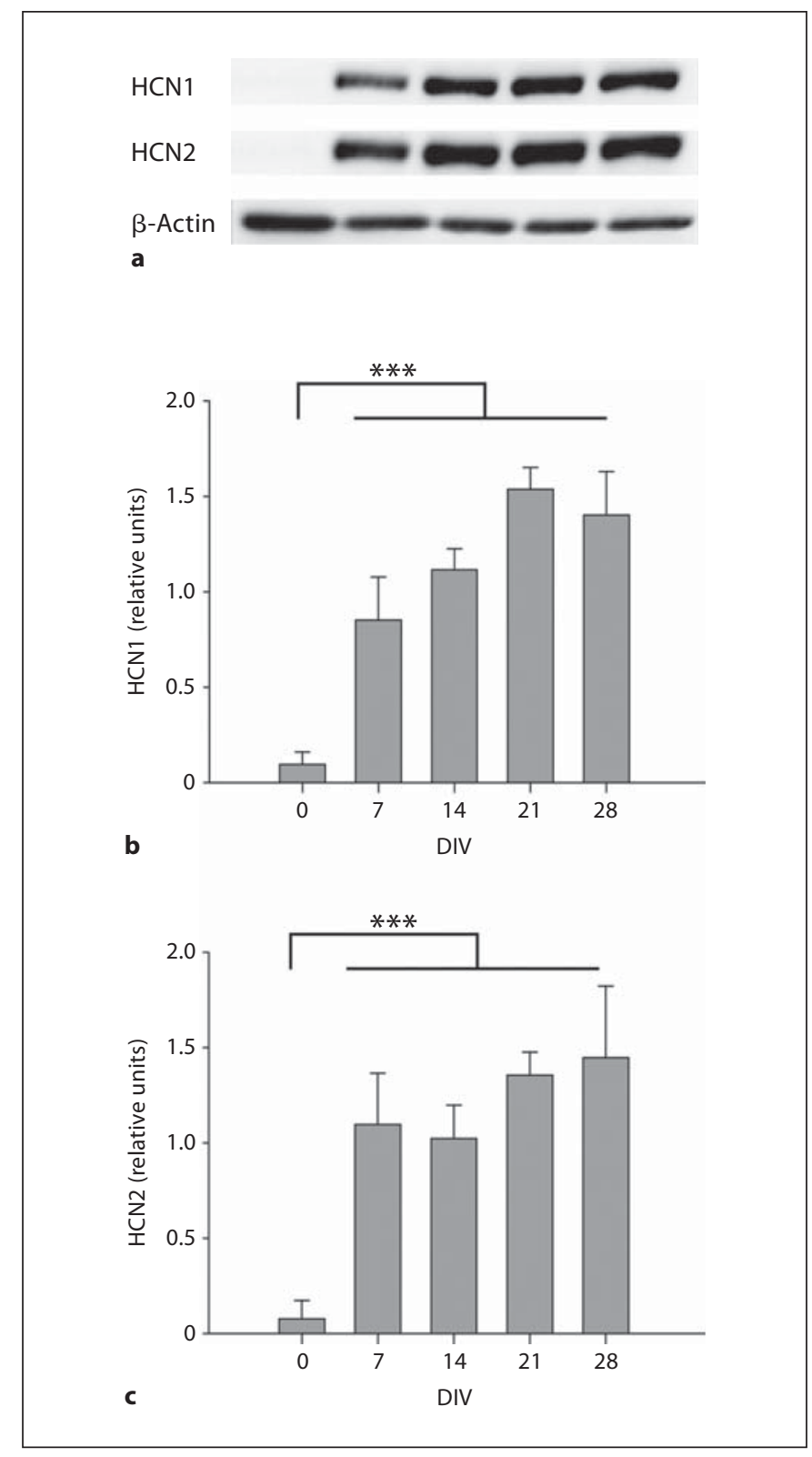

Fig. 7. Quantitative Western blot analysis of $\mathrm{HCN} 1$ and $\mathrm{HCN} 2$ protein expression in mouse cortical cultures. HCN1 (a, b) and HCN2 (a, c) immunoreactive bands were normalized to in-lane loading control, $\beta$-actin, and then expressed as a fraction of the mean density values of all bands in single gels. Each bar represents mean \pm SEM of four blots from two independent experiments. ${ }^{* * *} \mathrm{p}<0.001$.

Developmental Regulation and Subcellular Localization of HCN Subunits

HCN channels are abundant in cultured cortical networks. Quantitative Western blot analysis of HCN sub- unit expression showed an age-dependent upregulation of HCN1 and HCN2 isoforms in mouse cortical cultures. This result suggests that $\mathrm{HCN} 1$ and $\mathrm{HCN} 2$ are the major subunits in mature networks, which corresponds very well to the HCN channel pattern expressed by hippocampal fast-spiking basket cells obtained by single-cell RTqPCR analysis [17]. In other neuronal populations of the hippocampal CA3 region also the HCN4 subunit is expressed, suggesting that there is a cell-type-selective and subunit-specific expression pattern of $\mathrm{HCN}$ channels [30].

Immunocytochemistry showed that $\mathrm{HCN}$ channels are readily detected in the somatodendritic surface of both GABAergic L-INs and PNs. Specific localization of HCN channels to GABAergic basket neurons has also been found in the medial septum [31], hippocampus [17] and cerebellum [32]. In these interneurons, three of the four known HCN channel isoforms (HCN1, 2, 4) seem to be expressed preferentially at somatic and axonal localizations. Our results suggest that $\mathrm{HCN}$ channels are also expressed in presynaptic terminals of L-INs, because ZD7288 and $\mathrm{Cs}^{+}$reduced the frequency of mGABAPSCs recorded from PNs. These data confirm results from hippocampal dentate gyrus [17], where $\mathrm{HCN}$ channels have been found in somatodendritic and axonal compartments of fast-spiking basket-cell interneurons.

Recently, HCN1 channels were demonstrated at the active zone of mature glutamatergic synaptic terminals of cortical projection neurons, establishing contact with entorhinal cortical layer III cells, where they are involved in regulation of $\mathrm{Ca}^{2+}$ influx via presynaptic T-type $\left(\mathrm{Ca}_{v} 3.2\right)$ $\mathrm{Ca}^{2+}$ channels [33].

\section{What Is the Contribution of $I_{h}$ to Early Network \\ Activity?}

Instead of $\mathrm{I}_{\mathrm{h}}$, a persistent $\mathrm{Na}^{+}$current $\left(\mathrm{I}_{\mathrm{Nap}}\right.$ ) has been found to account for the slow depolarization following a firing-evoked afterhyperpolarization in CA3 pyramidal cells of the immature hippocampus [34]. Moreover, recurrent burst activity is promoted by a tonically depolarizing action of GABA in immature CA3 pyramidal neurons [35]. In the present study, ZD7288 concentrations as low as $1 \mu \mathrm{M}$ significantly reduced the SBA frequency. This correlates well with the expected increase in interburst intervals by blocking $\mathrm{I}_{\mathrm{h}}$. At this concentration, unspecific effects of ZD7288 on SBA frequency mediated by inhibition of T-type calcium currents [22] can be largely ruled out. Moreover, $\mathrm{I}_{\mathrm{h}}$-independent depression of synaptic transmission, as reported for hippocampal mossy fibers [36], seems not to contribute to the effects of low 
doses of ZD7288 (1 $\mu \mathrm{M})$ on SBA frequency, as observed in the present study.

Somatodendritic and axonal HCN channels have been found in fast-spiking basket-cell interneurons in the hippocampus, where they are thought to be involved in amplification and synchronization of network activity [17]. A contribution of $I_{h}$ to the maintenance of giant depolarizing potentials (GDPs) during early network maturation has been described for hilus and CA3 regions of the hippocampus $[14,16,37]$. However, the exact role of $I_{h}$ in generation and persistence of GDPs in the hippocampus is still controversial. Pacemaker currents mediated by HCN channels in hilar interneurons have been demonstrated to contribute critically to GDPs [16]. Interneurons of the CA3 region, in contrast, although able to generate a prominent voltage sag during hyperpolarization, did not show spontaneous bursting [14].

In neocortical cultures, the mechanisms involved in the generation and maintenance of SBA may be distinct from hippocampal GDPs. Recently, attention has been drawn to the variety of early network activity patterns [38]. In cortical slices, 'cortical early network oscillations' (cENOs) occur right after birth in rodents. After a week, a pattern emerges that is similar to hippocampal GDPs, with lower amplitude and higher frequency range than cENOs. In young neocortical cultures, the large and slow spontaneous bursting activity resemble cENOs recorded in cortical slices $[2,38,39]$ and cortical slice cultures [40].

Calcium-imaging data analyzing the $\left[\mathrm{Ca}^{2+}\right]_{\mathrm{i}}$ of identified L-INs in comparison with the surrounding neuronal network in cortical cultures clearly show the leading role of these cells during the onset of the synchronized calcium events [20]. Moreover, the occurrence of synchronous oscillatory activity in immature rat cortical cultures is strongly correlated with the presence of large GABAergic preplate neurons [20]. Due to their extensive axonal projections, these L-INs are optimally suited to synchronize oscillatory network activity in cortical networks [20,41]. A similar role for long-range GABAergic interneurons was recently described for hippocampal networks [42].
$I_{h}$ has been considered a source of tonic excitatory drive promoting the emergence of oscillations in interneuronal networks [43]. In hippocampal fast-spiking basket cells, this has been demonstrated to have stabilizing effects on firing and coherence of gamma oscillations [44]. Furthermore, medial septum GABAergic and parvalbumin/HCN-immunoreactive neurons were shown to serve as pacemakers of hippocampal theta rhythmic activity via the synchronization of hippocampal interneurons in vivo $[45,46]$. Based on the present data and morphological features of L-INs [20], we suggest that L-INs are essential for the synchronization of SBA and may also contribute to the maintenance of SBA during maturation of cortical networks. During its limited expression between neurogenesis and the onset of experience-dependent plasticity, the large-scale synchronized early network oscillations are essential to neuronal survival [47], to the setup of proper long-range network wiring [48-50], and to the development of local circuits [51, 52].

According to our results, $\mathrm{I}_{\mathrm{h}}$ plays a prominent role in increasing the pace of early SBA. Interestingly, the developmental increase of $\mathrm{I}_{\mathrm{h}}$, which reaches adult expression levels at the end of the second week in vivo, has also been suggested to contribute to desynchronization of early network bursting by limiting action potential firing during correlated network events [53]. However, the role of $I_{h}$ might change from promoting synchronization of SBA at early stages of development to de-correlating SBA at later stages. Accordingly, developmental and activity-dependent changes in channel structure and properties [54, 55] might contribute to a shifted role of $\mathrm{I}_{\mathrm{h}}$ in network activity.

\section{Acknowledgements}

Supported by the Federal State of Saxony-Anhalt and the European Regional Development Fund (ERDF 2007-2013). We thank Prof. Volkmar Lessmann for encouragement and helpful discussions, and Mrs. B. Adam and Mrs. A. Ritter for excellent technical assistance. Thanks are due to Drs. Y. Yanagawa and K. Obata for friendly providing GAD67-GFP $(\Delta$ neo) mice.

\section{References}

$\mathrm{I}_{\mathrm{h}}$ Current in Cortical Cultures
1 Khazipov R, Luhmann H: Early patterns of electrical activity in the developing cerebral cortex of human and rodents. Trends Neurosci 2006;29:414-418.

2 Garaschuk O, Linn J, Eilers J, Konnerth A: Large-scale oscillatory calcium waves in the immature cortex. Nat Neurosci 2000;3:452459.

-3 Opitz T, de Lima AD, Voigt T: Spontaneous development of synchronous oscillatory ac- tivity during maturation of cortical networks in vitro. J Neurophysiol 2002;88: 2196-2206.

4 Conhaim J, Cedarbaum ER, Barahimi M, Moore JG, Becker MI, Gleiss H, Kohl C, Moody WJ: Bimodal septal and cortical triggering and complex propagation patterns of spontaneous waves of activity in the developing mouse cerebral cortex. Dev Neurobiol 2010;70:679-692. 
5 Le Bon-Jego M, Yuste R: Persistently active, pacemaker-like neurons in neocortex. Front Neurosci 2007;1:123-129.

-6 Sheroziya MG, von Bohlen Und Halbach O, Unsicker K, Egorov AV: Spontaneous bursting activity in the developing entorhinal cortex. J Neurosci 2009;29:12131-12144.

7 Pape HC: Queer current and pacemaker: the hyperpolarization-activated cation current in neurons. Annu Rev Physiol 1996;58:299327.

$\checkmark 8$ Lupica CR, Bell JA, Hoffman AF, Watson PL: Contribution of the hyperpolarization-activated current $(\mathrm{I}(\mathrm{h}))$ to membrane potential and GABA release in hippocampal interneurons. J Neurophysiol 2001;86:261-268.

9 Beaumont V, Zucker RS: Enhancement of synaptic transmission by cyclic AMP modulation of presynaptic Ih channels. Nat Neurosci 2000;3:133-141.

10 Magee JC: Dendritic hyperpolarization-activated currents modify the integrative properties of hippocampal CA1 pyramidal neurons. J Neurosci 1998;18:7613-7624.

$\checkmark 11$ Magee JC: Dendritic lh normalizes temporal summation in hippocampal CA1 neurons. Nat Neurosci 1999;2:508-514.

12 Maccaferri G, McBain CJ: The hyperpolarization-activated current (Ih) and its contribution to pacemaker activity in rat CA1 hippocampal stratum oriens-alveus interneurones. J Physiol 1996;497:119-130.

$\checkmark 13$ Picken Bahrey HL, Moody WJ: Early development of voltage-gated ion currents and firing properties in neurons of the mouse cerebral cortex. J Neurophysiol 2003;89:17611773.

- 14 Bender RA, Galindo R, Mameli M, Gonzalez-Vega R, Valenzuela CF, Baram TZ: Synchronized network activity in developing rat hippocampus involves regional hyperpolarization-activated cyclic nucleotide-gated (HCN) channel function. Eur J Neurosci 2005;22:2669-2674.

-15 Brown RE, McKenna JT, Winston S, Basheer R, Yanagawa Y, Thakkar MM, McCarley RW: Characterization of GABAergic neurons in rapid-eye-movement sleep controlling regions of the brainstem reticular formation in GAD67-green fluorescent protein knock-in mice. Eur J Neurosci 2008;27:352-363.

- 16 Strata F, Atzori M, Molnar M, Ugolini G, Tempia F, Cherubini E: A pacemaker current in dye-coupled hilar interneurons contributes to the generation of giant GABAergic potentials in developing hippocampus. J Neurosci 1997; 17:1435-1446.

$\checkmark 17$ Aponte Y, Lien CC, Reisinger E, Jonas P: Hyperpolarization-activated cation channels in fast-spiking interneurons of rat hippocampus. J Physiol 2006;574:229-243.

-18 Tamamaki N, Yanagawa Y, Tomioka R, Miyazaki J, Obata K, Kaneko T: Green fluorescent protein expression and colocalization with calretinin, parvalbumin, and somatostatin in the GAD67-GFP knock-in mouse. J Comp Neurol 2003;467:60-79.
19 Klueva J, Meis S, de Lima AD, Voigt T, Munsch T: Developmental downregulation of GABAergic drive parallels formation of functional synapses in cultured mouse neocortical networks. Dev Neurobiol 2008;68: 934-949.

20 Voigt T, Opitz T, de Lima AD: Synchronous oscillatory activity in immature cortical network is driven by GABAergic preplate neurons. J Neurosci 2001;21:8895-8905.

21 Chen C: ZD7288 inhibits postsynaptic glutamate receptor-mediated responses at hippocampal perforant path-granule cell synapses. Eur J Neurosci 2004;19:643-649.

22 Sánchez-Alonso JL, Halliwell JV, Colino A: ZD7288 inhibits T-type calcium current in rat hippocampal pyramidal cells. Neurosci Lett 2008;439:275-280.

23 Biel M, Wahl-Schott C, Michalakis S, Zong $\mathrm{X}$ : Hyperpolarization-activated cation channels: from genes to function. Physiol Rev 2009;89:847-885

24 Harris-Warrick RM, Coniglio LM, Levini RM, Gueron S, Guckenheimer J: Dopamine modulation of two subthreshold currents produces phase shifts in activity of an identified motoneuron. J Neurophysiol 1995;74: 1404-1420.

25 Yue BW, Huguenard JR: The role of H-current in regulating strength and frequency of thalamic network oscillations. Thalamus Relat Syst 2001;1:95-103.

26 Giesbrecht CJ, Mackay JP, Silveira HB, Urban JH, Colmers WF: Countervailing modulation of Ih by neuropeptide $\mathrm{Y}$ and corticotrophin-releasing factor in basolateral amygdala as a possible mechanism for their effects on stress-related behaviors. J Neurosci 2010; 30:16970-16982.

27 O’Connell AD, Morton MJ, Sivaprasadarao A, Hunter M: Selectivity and interactions of $\mathrm{Ba}^{2+}$ and $\mathrm{Cs}^{+}$with wild-type and mutant TASK1 $\mathrm{K}^{+}$channels expressed in Xenopus oocytes. J Physiol 2005;562:687-696.

28 Meuth SG, Budde T, Kanyshkova T, Broicher T, Munsch T, Pape HC: Contribution of TWIK-related acid-sensitive $\mathrm{K}^{+}$channel 1 (TASK1) and TASK 3 channels to the control of activity modes in thalamocortical neurons. J Neurosci 2003;23:6460-6469.

29 Karschin C, Wischmeyer E, Preisig-Müller R, Rajan S, Derst C, Grzeschik KH, Daut J, Karschin A: Expression pattern in brain of TASK-1, TASK-3, and a tandem pore domain $\mathrm{K}(+)$ channel subunit, TASK-5, associated with the central auditory nervous system. Mol Cell Neurosci 2001;18:632-648.

30 Brewster AL, Chen Y, Bender RA, Yeh A, Shigemoto R, Baram TZ: Quantitative analysis and subcellular distribution of mRNA and protein expression of the hyperpolarizationactivated cyclic nucleotide-gated channels throughout development in rat hippocampus. Cereb Cortex 2007;17:702-712.
31 Varga V, Hangya B, Kranitz K, Ludanyi A, Zemankovics R, Katona I, Shigemoto R, Freund TF, Borhegyi Z: The presence of pacemaker HCN channels identifies theta rhythmic GABAergic neurons in the medial septum. J Physiol 2008;586:3893-3915.

32 Lujan R, Albasanz JL, Shigemoto R, Juiz JM: Preferential localization of the hyperpolarization-activated cyclic nucleotide-gated cation channel subunit HCN1 in basket cell terminals of the rat cerebellum. Eur J Neurosci 2005;21:2073-2082.

>33 Huang Z, Lujan R, Kadurin I, Uebele VN, Renger JJ, Dolphin AC, Shah MM: Presynaptic HCN1 channels regulate $\mathrm{Ca}(\mathrm{V}) 3.2$ activity and neurotransmission at select cortical synapses. Nat Neurosci 2011;14:478-486.

>34 Sipilä ST, Huttu K, Voipio J, Kaila K: Intrinsic bursting of immature CA3 pyramidal neurons and consequent giant depolarizing potentials are driven by a persistent $\mathrm{Na}^{+}$current and terminated by a slow $\mathrm{Ca}^{2+}$-activated $\mathrm{K}^{+}$current. Eur J Neurosci 2006;23:23302338.

35 Sipilä ST, Huttu K, Soltesz I, Voipio J, Kaila $\mathrm{K}$ : Depolarizing GABA acts on intrinsically bursting pyramidal neurons to drive giant depolarizing potentials in the immature hippocampus. J Neurosci 2005;25:52805289.

36 Chevaleyre V, Castillo PE: Assessing the role of Ih channels in synaptic transmission and mossy fiber LTP. PNAS 2002;99:95389543.

37 Bender RA, Brewster A, Santoro B, Ludwig A, Hofmann F, Biel M, Baram TZ: Differential and age-dependent expression of hyperpolarization-activated, cyclic nucleotidegated cation channel isoforms 1-4 suggests evolving roles in the developing rat hippocampus. Neurosci 2001;106:689-698.

$\checkmark 38$ Allène C, Cattani A, Ackman JB, Bonifazi P, Aniksztejn L, Ben-Ari Y, Cossart R: Sequential generation of two distinct synapse-driven network patterns in developing neocortex. J Neurosci 2008;28:12851-12863.

39 Baltz T, de Lima AD, Voigt T: Contribution of GABAergic interneurons to the development of spontaneous activity patterns in cultured neocortical networks. Front Cell Neurosci 2010;4:15

40 McCabe AK, Chisholm SL, Picken Bahrey HL, Moody WJ: The self-regulating nature of spontaneous synchronized activity in developing mouse cortical neurones. J Physiol 2006;577:155-167.

$\checkmark 4$ de Lima AD, Voigt T: Identification of two distinct populations of GABAergic neurons in cultures of the rat cerebral cortex. J Comp Neurol 1997;388:526-541.

42 Bonifazi P, Goldin M, Picardo MA, Jorquera I, Cattani A, Bianconi G, Represa A, Ben-Ari Y, Cossart R: GABAergic hub neurons orchestrate synchrony in developing hippocampal networks. Science 2009;326:14191424. 
43 Wang XJ, Buzsáki G: Gamma oscillation by synaptic inhibition in a hippocampal interneuronal network model. J Neurosci 1996; 16:6402-6413.

44 Vida I, Bartos M, Jonas P: Shunting inhibition improves robustness of gamma oscillations in hippocampal interneuron networks by homogenizing firing rates. Neuron 2006; 49:107-117.

45 Borhegyi Z, Varga V, Szilágyi N, Fabo D, Freund TF: Phase segregation of medial septal GABAergic neurons during hippocampal theta activity. J Neurosci 2004;24:84708479.

46 Hangya B, Borhegyi Z, Szilágyi N, Freund TF, Varga V: GABAergic neurons of the medial septum lead the hippocampal network during theta activity. J Neurosci 2009;29: 8094-8102.
47 Voigt T, Baier H, de Lima AD: Synchronization of calcium activity promotes survival of individual rat neocortical neurons in early development. Eur J Neurosci 1997;9:990999.

48 Katz LC, Shatz CJ: Synaptic activity and the construction of cortical circuits. Science 1996;274:1133-1138.

-49 Ben-Ari Y: Developing networks play a similar melody. Trends Neurosci 2001;24:353360.

50 Voigt T, Opitz T, de Lima AD: Activation of early silent synapses by spontaneous synchronous network activity limits the range of neocortical connections. J Neurosci 2005;25: 4605-4615.

51 Moody WJ, Bosma MM: Ion channel development, spontaneous activity, and activitydependent development in nerve and muscle cells. Physiol Rev 2005;85:883-941.
52 Blankenship AG, Feller MB: Mechanisms underlying spontaneous patterned activity in developing neural circuits. Nat Rev Neurosci 2010;11:18-29.

53 Golshani P, Goncalves JT, Khoshkhoo S, Mostany R, Smirnakis S, Portera-Cailliau C: Internally mediated developmental desynchronization of neocortical network activity. J Neurosci 2009;29:10890-10899.

54 Surges R, Brewster AL, Bender RA, Beck H, Feuerstein TJ, Baram TZ: Regulated expression of HCN channels and cAMP levels shape the properties of the $h$ current in developing rat hippocampus. Eur J Neurosci 2006;24:94-104.

55 Bender RA, Baram TZ: Hyperpolarization activated cyclic-nucleotide gated (HCN) channels in developing neuronal networks. Prog Neurobiol 2008;86:129-140. 